\title{
Seleção e agrupamento de indicadores da qualidade de águas utilizando Estatística Multivariada
}

\author{
Selection and grouping of indicators of water quality using \\ Multivariate Statistics
}

\author{
Ana Paula Almeida Bertossi ${ }^{1 *}$; João Paulo Cunha de Menezes ${ }^{1}$; \\ Roberto Avelino Cecílio ${ }^{2}$; Giovanni de Oliveira Garcia²; Mirna Aparecida Neves ${ }^{2}$
}

\begin{abstract}
Resumo
No presente trabalho empregaram-se técnicas de Estatística Multivariada (Análise de Componentes Principais e Análise de Agrupamento Hierárquico) com o objetivo de selecionar as características físico-químicas mais importantes para explicar a variabilidade da qualidade das águas de uma sub-bacia hidrográfica rural no Sul do Estado do Espírito Santo, além de agrupar as águas estudadas quanto à similaridade das características selecionadas para verificar o efeito do tipo de cobertura do solo (agrícola, pecuário, florestal e urbano), de recurso hídrico (subterrâneo e superficial) e período de coleta (chuva e estiagem). A análise físico-química das águas foi feita por meio da determinação de $\mathrm{pH}$, condutividade elétrica, sólidos totais, sólidos dissolvidos, sólidos suspensos, turbidez, demanda bioquímica de oxigênio (DBO), nitrogênio amoniacal, nitrato, nitrito, fósforo total, $\mathrm{Ca}, \mathrm{Mg}, \mathrm{Fe}, \mathrm{Na}, \mathrm{K}, \mathrm{Zn}, \mathrm{Cu}$ e coliformes totais. A Análise de Componentes Principais promoveu a redução de dezenove parâmetros de qualidade em três componentes que explicaram $87,53 \%$ da variância total. As características mais representativas da variabilidade da qualidade das águas estudadas foram: condutividade elétrica, sólidos totais, sólidos dissolvidos, turbidez, $\mathrm{DBO}$, nitrato, $\mathrm{Ca}, \mathrm{Mg}$ e $\mathrm{Na}$. Na Análise de Agrupamento Hierárquico foram formados quatro grupos distintos de qualidade da água que diferiram quanto à concentração das características físico-químicas e quanto ao tipo de recurso hídrico estudado, já os períodos de coleta e o tipo de cobertura do solo não influenciaram na segregação dos grupos formados.
\end{abstract}

Palavras-chave: Análise de componentes principais, análise de agrupamento, qualidade da água

\begin{abstract}
Multivariate statistics techniques (Principal Component Analysis and Cluster Analysis) were employed to select the most important parameters that explain water quality variability at a rural watershed in the state of Espírito Santo (Brazil). In addition to group the waters studied for the similarity of features selected to verify the effect of type of soil cover (agriculture, livestock, forest and urban), water resource (surface and underground) and sampling period (rainy and dry seasons). Nineteen physico-chemical parameters of water quality were analyzed: $\mathrm{pH}$, electrical conductivity, total solids, total dissolved solids, total suspended solids, turbidity, biochemical oxygen demand (BOD), ammoniacal nitrogen, nitrate, nitrite, total phosphorous, $\mathrm{Ca}, \mathrm{Mg}, \mathrm{Fe}, \mathrm{Na}, \mathrm{K}, \mathrm{Zn}, \mathrm{Cu}$ and total coliform. Application of Principal Component Analysis reduced the 19 parameters to three components that explained $87.53 \%$ of the total variance of data set. Water quality parameters that best explained variability of data were: electrical conductivity, total solids, total dissolved solids, turbidity, $\mathrm{BOD}$, nitrate, $\mathrm{Ca}, \mathrm{Mg}$, and $\mathrm{Na}$. Application of
\end{abstract}

\footnotetext{
${ }^{1}$ Discente(s) de pós-graduação da Universidade Federal do Espírito Santo, UFES, Centro de Ciências Agrárias, CCA, Alto Universitário s/n., Alegre, ES. E-mail: anapaulabertossi@yahoo.com.br; jpaulo_bio@hotmail.com

2 Profs. da Universidade Federal do Espírito Santo, UFES, Centro de Ciências Agrárias, CCA, Alto Universitário s/n., Alegre, ES. E-mail: racecilio@yahoo.com.br; giovanni.garcia@ufes.br; mirnaan@gmail.com

* Autor para correspondência
} 
Cluster Analysis showed four different groups of water quality that differed in concentration of physicochemical characteristics and the type of water resource study, since the collection periods and the type of soil cover did not influence the segregation of groups formed.

Key words: Principal component analysis, cluster analysis, water quality

\section{Introdução}

De acordo com Mendonça e Leitão (2008), o problema da qualidade da água e da gestão dos recursos hídricos consiste em um dos mais graves da sociedade contemporânea. O conhecimento sobre a qualidade dos recursos hídricos de uma bacia consiste, portanto, em ferramenta de extrema importância, uma vez que a partir dessas informações é possível inferir sobre as condições da bacia hidrográfica como um todo (QUEIROZ et al., 2010).

Para se conhecer a qualidade real da água de um corpo hídrico é imprescindível não somente a avaliação pontual de suas características físicas, químicas e microbiológicas, mas também do monitoramento de sua variabilidade espacial e sazonal. Segundo Braga, Porto e Tucci (2006) essas são atividades necessárias não apenas para que se conheça a situação dos corpos hídricos com relação aos impactos sofridos na bacia hidrográfica, mas também para que ações de controle e melhoria da qualidade ambiental sejam propostas e promovidas.

A realização de um monitoramento espaçotemporal consistente envolve a determinação de muitas características da água em vários locais e períodos, o que gera um grande número de informações correlacionadas. Todavia, apenas uma pequena quantidade destes dados pode conter informações relevantes, enquanto a maioria das variáveis pouco pode adicionar em termos de informações importantes para caracterização da qualidade das águas (SIMEONOV et al., 2003; ANDRADE et al., 2007a). Tal fato frequentemente torna difícil a interpretação dos dados coletados para adoção de medidas mitigadoras dos impactos ambientais sofridos pelas bacias hidrográficas.
Para interpretar este grande conjunto de dados qualitativos, técnicas de estatística multivariada como a Análise de Componentes Principais (ACP) e a Análise de Agrupamento Hierárquico (AAH) vêm sendo largamente utilizadas em estudos de caracterização e monitoramento de qualidade da água (MENDIGUCHÍA et al., 2004; ANDRADE et al., 2007a, 2007b; GIRÃO et al., 2007; KAZI et al., 2009; PALÁCIO et al., 2009; TOBISZEWSKI et al., 2010; PALÁCIO et al., 2011).

Este tipo de análise permite reduzir a informação contida em um número de variáveis originais em um conjunto menor de variáveis estatísticas (fatores) com perda mínima de informação (HAIR et al., 2005). Possibilita, ainda, identificar as variáveis que são responsáveis pela dispersão das observações e evidenciar possíveis agrupamentos, de acordo com seu grau de similaridade ou dissimilaridade (ANDRADE; SILVEIRA; AZEVEDO, 2003). Por meio das componentes principais, é possível selecionar aquelas características de maior participação em cada componente e definir as características físico-químicas da água que deverão ser monitoradas, reduzindo-se, assim, os custos com análises de características de menor importância na qualidade das águas.

No presente trabalho empregou-se a técnica da estatística multivariada com o objetivo de: i) avaliar as características físico-químicas da água mais importantes para explicar a variabilidade da qualidade das águas superficiais e subterrâneas de uma sub-bacia hidrográfica rural no Sul do Estado do Espírito Santo e ii) agrupar as águas estudadas quanto à similaridade das características físicoquímicas selecionadas para verificar o efeito do tipo de cobertura do solo (agrícola, pecuário, florestal e urbano), de recurso hídrico (subterrâneo e superficial) e período de coleta (chuva e estiagem). 


\section{Material e Métodos}

A área estudada consistiu na Sub-bacia Hidrográfica do Córrego Horizonte, localizada entre as coordenadas geográficas $41^{\circ} 32^{\prime}$ e $41^{\circ} 38^{\prime}$ de longitude Oeste e $20^{\circ} 43^{\prime}$ e $20^{\circ} 51^{\prime}$ de latitude Sul, com área aproximada de 1.265,36 ha, situada no distrito de Rive, município de Alegre (ES). Segundo a classificação de Köppen, o clima da região é do tipo Cwa, caracterizado pelo inverno seco e verão chuvoso.

Foram coletadas amostras de água superficial (SUP) e subterrânea (SUB) em diferentes locais da sub-bacia estudada, cada um sob influência de diferentes usos do solo: florestal, agrícola, pecuário e urbano. As coletas foram realizadas duas vezes ao ano, uma no período de estiagem (E) e outra no período de chuvas (C). Na Figura 1 estão apresentados os pontos de coleta de água, onde: $\mathrm{URBj}$ = água superficial coletada à jusante da área urbana, URBm = águas subterrâneas e superficiais coletadas à montante da área urbana, PAS, FLO e $\mathrm{CAF}=$ águas subterrâneas e superficiais coletadas nos exutórios de microbacias de cabeceira, cada qual coberta unicamente por um único tipo de uso do solo: pastagem, floresta e cafeicultura, respectivamente.

Figura 1. Localização dos pontos de amostragem de águas superficiais e subterrâneas na Sub-bacia Hidrográfica do Córrego Horizonte, onde: $\mathrm{URBj}$ = água superficial coletada à jusante da área urbana, URBm = águas subterrâneas e superficiais coletadas à montante da área urbana, PAS, FLO e CAF = águas subterrâneas e superficiais coletadas em pontos sob influência de pastagem, floresta e cafeicultura, respectivamente.

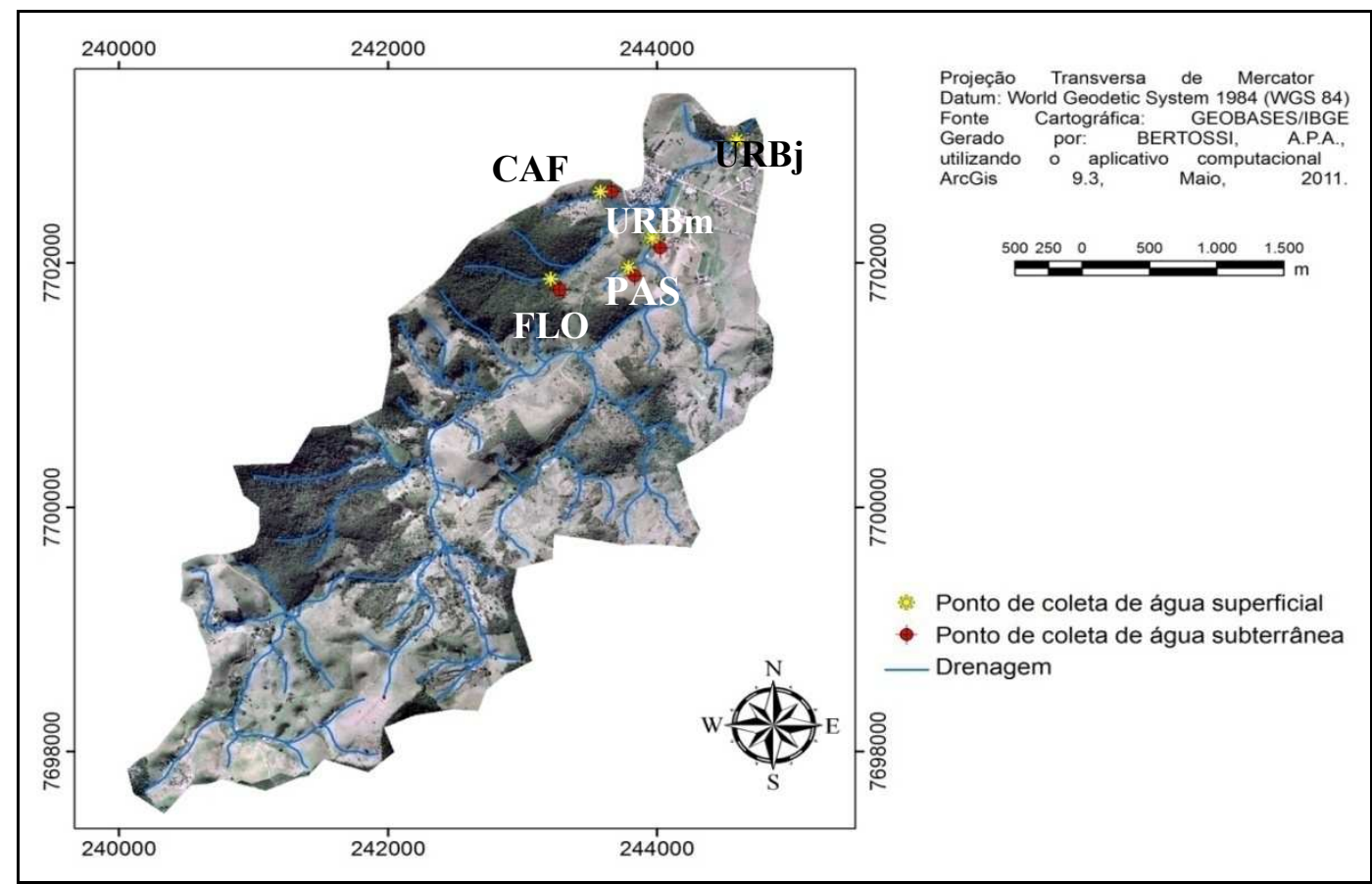

Fonte: Elaboração dos autores.

O ponto de coleta URBj foi caracterizado apenas pelo recurso hídrico superficial, pois o poço perfurado para coleta de água subterrânea estava seco nos dois períodos de coleta.
O corpo hídrico onde foram coletadas as amostras de água superficial sob influência da floresta e da cafeicultura, é caracterizado como um ambiente lêntico, ou seja, com águas de movimento 
reduzido, enquanto as outras amostras de água foram coletadas em ambientes lóticos, ou seja, em águas correntes.

A área urbana estudada constitui uma pequena comunidade, com aproximadamente 3,5 mil habitantes, onde há lançamento de esgoto não tratado diretamente no corpo hídrico receptor.

A análise físico-química das águas foi feita por meio da determinação do $\mathrm{pH}$, turbidez (T) e condutividade elétrica (CE) utilizandose os equipamentos peagâmetro, turbidímetro e condutivímetro respectivamente, para cada parâmetro. Sólidos totais (ST), sólidos dissolvidos (STD) e sólidos suspensos (SS) pelo método gravimétrico proposto na NBR 10664 (ABNT, 1989a). DBO obtida de acordo com a NBR 12614 (ABNT, 1992a). Nitrogênio amoniacal $\left(\mathrm{NH}_{4}^{+}\right)$, nitrato $\left(\mathrm{NO}_{3}^{-}\right)$, nitrito $\left(\mathrm{NO}_{2}^{-}\right)$e fósforo total $(\mathrm{P}$ total) determinados por meio de espectroscopia UV/VIS, conforme as metodologias descritas na NBR 10560 (ABNT, 1988), NBR 12620 (ABNT, 1992b), NBR 12619 (ABNT, 1992c) e NBR 12772 (ABNT, 1992d), respectivamente, para cada parâmetro. Leitura das concentrações de cálcio, magnésio, ferro, sódio, potássio, zinco e cobre no espectrofotômetro de absorção atômica por chama, segundo a metodologia da NBR 13810 (ABNT, 1997) e coliformes totais (Col. total) pela técnica dos tubos múltiplos segundo a NBR 11259 (ABNT, 1989b).

Foi aplicada a estatística multivariada através da análise de componentes principais (ACP) para avaliar a importância de cada parâmetro e promover a eliminação daqueles que contribuíssem pouco, em termos de variação espacial e sazonal, para a qualidade das águas estudadas. A análise foi realizada no programa "R" versão 2.8.1 (R DEVELOPMENT CORE TEAM, 2008). Para se eliminar o efeito de escala e unidades, a padronização dos dados processados foi realizada com a conversão das variáveis para escores padrões.

A seleção do número de componentes seguiu os preceitos apresentados por Hair et al. (2005), em que se consideram somente componentes com autovalor superior à unidade. Este critério fundamenta-se no fato de que qualquer componente deve explicar uma variância superior àquela apresentada por uma simples variável padronizada, que é um.

Após terem sido selecionadas as componentes principais, dentro destas foram escolhidas as variáveis que apresentaram coeficiente de correlação maior ou igual a 0,7 com as componentes selecionadas para comporem o índice de qualidade de água. Segundo Hair et al. (2005), ao se utilizar esse critério, seleciona-se as variáveis que apresentam coeficiente de determinação maior ou igual a 0,5 .

As características mais importantes para variação espacial e sazonal da qualidade das águas estudadas foram utilizadas para o estudo da semelhança entre os pontos de coleta de água, que foi realizado através da análise de agrupamento hierárquico (AAH) com o auxílio do programa " $\mathrm{R}$ ” versão 2.8.1 (R DEVELOPMENT CORE TEAM, 2008).

As amostras de água foram agrupadas com base na similaridade das características analisadas, definida pela variação entre os coeficientes de agrupamento de dois grupos consecutivos, conforme descrito por Hair et al. (2005). Como as variáveis utilizadas nesse estudo são reais, adotou-se a combinação da distância euclidiana ao quadrado para a formação da matriz de similaridade e o algoritmo do método de ligação Ward, conforme realizado por Fernandes et al. (2010) e Palácio et al. (2011). Os dados médios de cada parâmetro dos grupos formados foram submetidos à análise de variância (ANOVA) e aplicado o teste de Tukey para os valores significativos em nível de 5\% de significância.

\section{Resultados e Discussão}

Análise de componentes principais (ACP)

Pelos resultados da análise da componente principal (ACP), observou-se que um modelo com três componentes foi adequado para representar as 
características físico-químicas analisadas nas águas e explicar aproximadamente $87,53 \%$ da variância total.

A primeira, a segunda e a terceira componentes principais explicaram, respectivamente, 51,2\%; $20,22 \%$ e $16,11 \%$ da variância total dos dados, concentrando em três dimensões $87,53 \%$ das informações antes diluídas em 19 dimensões (número de variáveis analisadas). Resultados semelhantes foram encontrados por Girão et al. (2007) e Bhardwaj, Singh e Singh (2010), ao avaliarem a qualidade das águas dos rios Jaibaras (Ceará) e Chhoti Gandak (Índia), nos quais também foram selecionadas três componentes que, juntas, explicaram $80,19 \%$ e $77,97 \%$ da variância total, respectivamente. Já Andrade et al. (2007a), ao trabalharem com a técnica da Análise Fatorial/ Análise da Componente Principal, selecionaram quatro componentes indicadoras da qualidade das águas superficiais estudadas, que, juntas, explicaram $82,1 \%$ da variância total. No presente trabalho, foram encontrados valores superiores, ou seja, com apenas três componentes foi possível explicar $87,53 \%$ da variância total dos dados. Melhores resultados foram obtidos por Kazi et al. (2009), no Lago Manchar (Paquistão), em que apenas três componentes principais representaram 97,6\% da variância total.

No presente trabalho, para a primeira componente principal foram selecionadas as variáveis condutividade elétrica, sólidos totais, sólidos dissolvidos, cálcio, magnésio e sódio; na segunda componente, as variáveis turbidez e nitrato e, na terceira, a variável DBO. Portanto, o modelo aplicado mostrou que para a primeira componente foram significativas as variáveis relacionadas com os sais dissolvidos na água; na segunda a variável relacionada com partículas em suspensão, tanto orgânicas, quanto inorgânicas; enquanto na terceira componente, os elementos relacionados com a poluição orgânica apresentaram maior significância. Variáveis semelhantes foram selecionadas por Andrade et al. (2007b) como as mais representativas da qualidade das águas da Bacia Hidrográfica do Alto Acaraú, no Ceará.

A análise de componentes principais promoveu boa redução no número de variáveis, na qual foram selecionadas 9 das 19 variáveis analisadas nas águas, ou seja, foram selecionadas aproximadamente 50\% das variáveis analisadas. De modo oposto, Andrade et al. (2007a) não obtiveram bons resultados ao aplicar a análise de componentes principais para reduzir o número de variáveis, uma vez que o melhor ajuste do modelo ocorreu com a inclusão de 18 das 25 variáveis analisadas.

A matriz de correlação composta pelas 9 variáveis selecionadas na $\mathrm{ACP}$, mostra a relação entre as variáveis selecionadas em cada componente (Tabela 1). Aproximadamente $50 \%$ dos coeficientes de correlação apresentam valores significativos em nível de $5 \%$ de probabilidade pelo Teste $t$, demonstrando um bom índice de correlação entre as variáveis de qualidade de água selecionadas na ACP. Tal fato demonstra que as variáveis estudadas compartilham fatores comuns (NORUSIS, 1990), ou seja, as variáveis selecionadas na componente 1 apresentam alta correlação entre si, assim como as selecionadas na componente 2. Já na componente 3 , apenas uma variável foi selecionada, por isso a DBO não apresenta correlação significativa com nenhuma outra variável. 
Tabela 1. Matriz de correlação das variáveis selecionadas na ACP.

\begin{tabular}{cccccccccc}
\hline & $\mathbf{T}$ & $\mathbf{C E}$ & $\mathbf{S T}$ & $\mathbf{S T D}$ & $\mathbf{N O}_{\mathbf{3}}^{-}$ & $\mathbf{D B O}$ & $\mathbf{C a}$ & $\mathbf{M g}$ & $\mathbf{N a}$ \\
$\mathbf{T}$ & 1,000 & & & & & & & & \\
$\mathbf{C E}$ & 0,067 & 1,000 & & & & & & & \\
$\mathbf{S T}$ & 0,424 & $0,851^{*}$ & 1,000 & & & & & & \\
$\mathbf{S T D}$ & 0,270 & $0,856^{*}$ & $0,887^{*}$ & 1,000 & & & & & \\
$\mathbf{N O}_{3}^{-}$ & $0,533^{*}$ & $-0,131$ & 0,085 & $-0,174$ & 1,000 & & & \\
$\mathbf{D B O}$ & 0,461 & 0,018 & 0,290 & 0,354 & $-0,065$ & 1,000 & & \\
$\mathbf{C a}$ & 0,044 & $0,922^{*}$ & $0,817^{*}$ & $0,840^{*}$ & $-0,090$ & $-0,062$ & 1,000 & & \\
$\mathbf{M g}$ & $-0,026$ & $0,966^{*}$ & $0,764^{*}$ & $0,805^{*}$ & $-0,169$ & $-0,094$ & $0,932^{*}$ & 1,000 & \\
$\mathbf{N a}$ & 0,111 & $0,728^{*}$ & $0,581^{*}$ & $0,669^{*}$ & $-0,179$ & 0,111 & $0,472^{*}$ & $0,638^{*}$ & 1,000 \\
\hline
\end{tabular}

* Valores significativos em nível de 5\% de probabilidade.

Fonte: Elaboração dos autores.

A condutividade elétrica, sólidos totais, sólidos dissolvidos, cálcio, magnésio e sódio apresentaram correlação significativa entre si, o que é coerente, já que essas variáveis influenciam umas nas outras (VON SPERLING, 2005). A condutividade elétrica está relacionada com a concentração iônica da solução. Os íons mais comumente associados à alteração da condutividade elétrica na água são o cálcio, o magnésio e o sódio, que também compõem os sólidos dissolvidos da água; estes, junto aos sólidos suspensos, compõem os sólidos totais (VON SPERLING, 2005).

A turbidez apresenta correlação significativa com o nitrato. Segundo Von Sperling (2005) a turbidez da água é influenciada pela presença de sólidos em suspensão que, além das partículas inorgânicas (areia, silte e argila) incluem também materiais orgânicos, o que pode explicar essa relação, já que o nitrato pode ser classificado como um componente orgânico da água (ANDRADE et al., 2005). O parâmetro DBO não apresentou correlação significativa com nenhuma das variáveis analisadas.

\section{Análise de agrupamento hierárquico (AAH)}

$\mathrm{Na}$ Figura 2 apresenta-se o dendograma referente ao AAH, no qual as águas da sub-bacia estudada (superficiais e subterrâneas) foram agrupadas quanto à similaridade das características de qualidade selecionadas como mais importantes na ACP. Observa-se que o ponto ótimo de corte para formação dos grupos de similaridade se encontra em $20 \%$, pois, a partir deste, ocorre o distanciamento maior na medida de similaridade para a formação dos grupos. Desta forma, definem-se quatro agrupamentos distintos. Palácio et al. (2011), ao avaliar a semelhança das águas superficiais do Ceará através da análise de agrupamento hierárquico, também encontraram quatro grupos distintos de similaridade, enquanto Kazi et al. (2009) e Fernandes et al. (2010) encontraram três grupos ao estudarem, respectivamente, as águas superficiais do Lago Manchar (Paquistão) e as águas subterrâneas do semiárido cearense.

Percebe-se que os grupos 3 e 4 foram os de maior representatividade, cada um com 33,3\% dos pontos de coletas de água estudados, sendo estes grupos formados, cada um, por 6 dos 18 pontos de água analisados. Os grupos 1 e 2 foram compostos, cada um, por 3 dos pontos de coleta de água estudados (16,7\%). Os grupos formados pela AAH apresentaram certa uniformidade quanto à quantidade de pontos de coleta de água por grupo, diferentemente de Palácio et al. (2011), que encontraram um grupo com $68,75 \%$ dos dados e outro com $2,08 \%$. 
Figura 2. Dendrograma das águas da Sub-bacia Hidrográfica do Córrego Horizonte agrupadas quanto às características de qualidade, sendo: $\mathrm{PAS}=$ pastagem, $\mathrm{FLO}=$ floresta, $\mathrm{CAF}=$ cafeicultura, $\mathrm{URBm}=$ urbano à montante, $\mathrm{URBj}=$ urbano à jusante, $\mathrm{SUP}=$ água superficial, $\mathrm{SUB}=$ água subterrânea, $\mathrm{E}=$ estiagem e $\mathrm{C}=$ chuva.

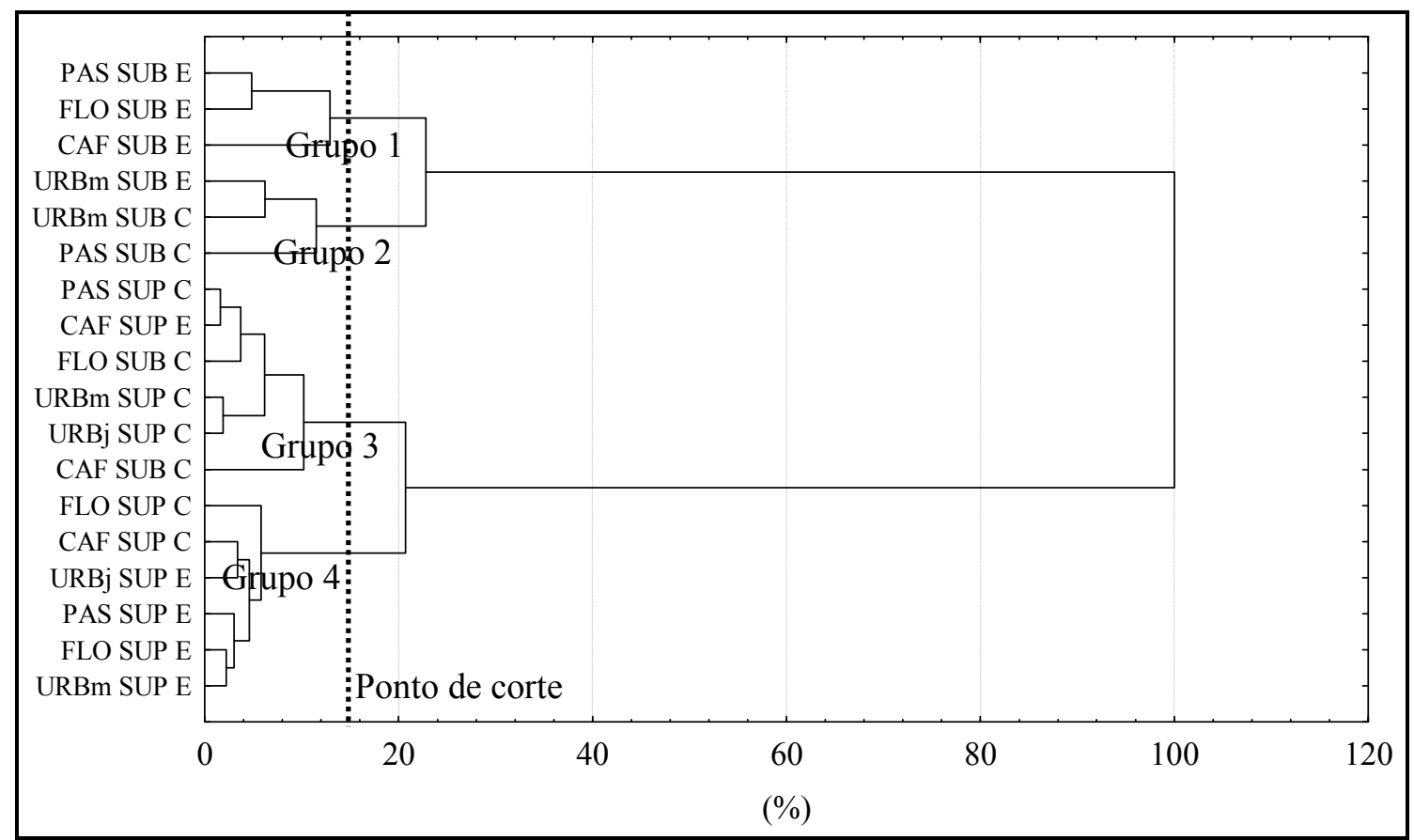

Fonte: Elaboração dos autores.

A maior similaridade foi registrada entre os pontos de coleta de água que compõem o grupo 4 , devido à distância (\%) na qual ocorreu a formação dos grupos. Pode-se perceber que o grupo 4 foi o primeiro a se formar, depois o terceiro, o segundo e o primeiro grupo.

Os valores médios, o desvio padrão (DP) e os valores máximos e mínimos dos parâmetros de qualidade das águas de cada um dos grupos estão apresentados na Tabela 2, junto ao teste de Tukey para os valores significativos em nível de $5 \%$ de significância. Observa-se que as características de qualidade que diferiram entre os grupos formados na análise multivariada foram a condutividade elétrica, os sólidos totais, os sólidos dissolvidos, a $\mathrm{DBO}$, o Ca, o Mg e o Na. Já a turbidez e o nitrato não interferiram na segregação estatística dos grupos.

Os grupos foram formados pela similaridade entre as concentrações das características de qualidade avaliadas, na qual se pode perceber que as características relacionadas com a mineralização das águas foram as que mais influenciaram na segregação dos grupos. Estas características foram selecionadas na primeira componente e explicam aproximadamente $50 \%$ da variabilidade total dos dados.

Os grupos 1 e 3 foram formados por águas que apresentaram concentrações intermediárias dos parâmetros de qualidade relacionados com a salinidade da água, o grupo 2 apresentou as maiores concentrações médias e o grupo 4, as menores.

As características de maior influência para a formação do grupo 1 foram a condutividade elétrica, os sólidos totais, os sólidos dissolvidos e a DBO, que diferiram dos demais grupos pelo teste de Tukey em nível de 5\% de significância. O grupo 1 foi formado por águas subterrâneas coletadas no período de estiagem nas microbacias ocupadas por pastagem, floresta e cafeicultura. Estas apresentaram valores intermediários das características relacionadas com 
a salinidade da água (CE, ST e STD) e os maiores valores relacionados à contaminação orgânica (DBO). Menezes et al. (2009) também encontraram valores elevados de DBO em águas subterrâneas, o que segundo os autores é reflexo do uso e da ocupação do solo na bacia e devido à contaminação com resíduos agrícolas e de criação de animais.

Tabela 2. Valores das características físico-químicas por grupo de similaridade da qualidade das águas da Sub-bacia Hidrográfica do Córrego Horizonte.

\begin{tabular}{|c|c|c|c|c|c|}
\hline & Estatística & Grupo 1 & Grupo 2 & Grupo 3 & Grupo 4 \\
\hline \multirow{3}{*}{$\begin{array}{c}\mathrm{T} \\
(\mathrm{UNT})\end{array}$} & Média \pm DP & $35,26 \pm 38,07 \mathrm{a}$ & $12,88 \pm 1,87 \mathrm{ab}$ & $17,5 \pm 15,18 \mathrm{ab}$ & $12,36 \pm 5,25 b$ \\
\hline & Mínimo & 9,58 & 11,71 & 1,33 & 6,26 \\
\hline & Máximo & 79,0 & 15,04 & 39,25 & 20,83 \\
\hline \multirow{3}{*}{$\begin{array}{c}\mathrm{CE} \\
\left(\mu \mathrm{S} \mathrm{cm}^{-1}\right)\end{array}$} & Média \pm DP & $203,98 \pm 6,58 b$ & $299,17 \pm 52,54 \mathrm{a}$ & $157,5 \pm 13,98 \mathrm{c}$ & $108,7 \pm 16,68 d$ \\
\hline & Mínimo & 197,95 & 263,50 & 137,00 & 80,25 \\
\hline & Máximo & 211,0 & 359,5 & 179,5 & 125,25 \\
\hline \multirow{3}{*}{$\begin{array}{c}\mathrm{ST} \\
\left(\mathrm{mg} \mathrm{L}^{-1}\right)\end{array}$} & Média \pm DP & $181,89 \pm 42,84 \mathrm{~b}$ & $224,49 \pm 10,57 \mathrm{a}$ & $116,53 \pm 26,64 \mathrm{c}$ & $84,55 \pm 13,15 d$ \\
\hline & Mínimo & 140,2 & 213,0 & 91,4 & 68,4 \\
\hline & Máximo & 225,8 & 233,8 & 167,8 & 99,83 \\
\hline \multirow{3}{*}{$\begin{array}{c}\mathrm{STD} \\
\left(\mathrm{mg} \mathrm{L}^{-1}\right)\end{array}$} & Média \pm DP & $147,17 \pm 28,11 b$ & $184,33 \pm 30,15 \mathrm{a}$ & $72,13 \pm 11,12 \mathrm{c}$ & $65,08 \pm 15,44 c$ \\
\hline & Mínimo & 122,0 & 150,8 & 56,8 & 47,5 \\
\hline & Máximo & 177,5 & 209,2 & 85,4 & 82,0 \\
\hline \multirow{3}{*}{$\begin{array}{c}\mathrm{NO}_{3}^{-} \\
\left(\mathrm{mg} \mathrm{L}^{-1}\right)\end{array}$} & Média \pm DP & $0,02 \pm 0,04 \mathrm{a}$ & $0,03 \pm 0,03 \mathrm{a}$ & $0,06 \pm 0,07 \mathrm{a}$ & $0,04 \pm 0,03 \mathrm{a}$ \\
\hline & Mínimo & 0,0 & 0,0 & 0,0 & 0,0 \\
\hline & Máximo & 0,07 & 0,05 & 0,16 & 0,07 \\
\hline \multirow{3}{*}{$\begin{array}{c}\mathrm{DBO} \\
\left(\mathrm{mg} \mathrm{L}^{-1}\right)\end{array}$} & Média \pm DP & $5,93 \pm 1,87 \mathrm{a}$ & $2,16 \pm 0,93 \mathrm{c}$ & $1,28 \pm 1,41 \mathrm{c}$ & $3,17 \pm 1,92 b$ \\
\hline & Mínimo & 4,86 & 1,62 & 0,0 & 1,21 \\
\hline & Máximo & 8,09 & 3,24 & 4,05 & 5,66 \\
\hline \multirow{3}{*}{$\begin{array}{c}\mathrm{Ca} \\
\left(\mathrm{mg} \mathrm{L}^{-1}\right)\end{array}$} & Média \pm DP & $9,41 \pm 2,74 b$ & $24,64 \pm 1,95 \mathrm{a}$ & $8,07 \pm 0,39 b$ & $4,98 \pm 1,02 \mathrm{c}$ \\
\hline & Mínimo & 6,68 & 22,81 & 7,57 & 3,85 \\
\hline & Máximo & 12,15 & 26,69 & 8,6 & 6,42 \\
\hline \multirow{3}{*}{$\begin{array}{c}\mathrm{Mg} \\
\left(\mathrm{mg} \mathrm{L}^{-1}\right)\end{array}$} & Média \pm DP & $3,84 \pm 0,09 \mathrm{~b}$ & $6,9 \pm 1,6 \mathrm{a}$ & $3,3 \pm 0,62 b$ & $1,92 \pm 0,35 \mathrm{c}$ \\
\hline & Mínimo & 3,77 & 5,81 & 2,82 & 1,42 \\
\hline & Máximo & 3,94 & 8,73 & 4,48 & 2,37 \\
\hline \multirow{3}{*}{$\begin{array}{c}\mathrm{Na} \\
\left(\mathrm{mg} \mathrm{L}^{-1}\right)\end{array}$} & Média \pm DP & $18,31 \pm 3,66 \mathrm{a}$ & $15,23 \pm 5,34 \mathrm{a}$ & $11,33 \pm 3,13 b$ & $6,92 \pm 0,53 \mathrm{c}$ \\
\hline & Mínimo & 14,53 & 11,27 & 8,2 & 5,87 \\
\hline & Máximo & 21,83 & 21,3 & 16,5 & 7,27 \\
\hline
\end{tabular}

Obs: Médias seguidas de letras iguais nas linhas não diferem no teste de Tukey em nível de 5\% de significância.

Fonte: Elaboração dos autores.

Provavelmente a DBO medida nas águas subterrâneas sob influência da floresta e da cafeicultura na época de estiagem se deve à queda das folhas que ocorre nessa época, já que os pontos de coleta são envoltos por árvores que podem ter contribuído com a matéria orgânica do solo nessas áreas. Já na microbacia com pastagem, os altos teores de DBO encontrados na época de estiagem podem estar associados à contaminação por excrementos de animais, conforme também relatado por Menezes et al. (2009). 
O grupo 2 também foi formado por águas subterrâneas, só que coletadas nos diferentes períodos de estudo (chuvoso e de estiagem). Os pontos de coleta de água consistiram na microbacia sob pastagem (período de chuva) e na seção a montante da área urbanizada (ambos os períodos). As características desse grupo que diferiram estatisticamente dos outros foram a condutividade elétrica, os sólidos totais, os sólidos dissolvidos, o cálcio e o magnésio, todas essas, relacionadas com a mineralização das águas. Os pontos de coleta desse grupo foram os que apresentaram os maiores valores das características relacionadas com a salinidade da água e juntamente com os do grupo 3, apresentaram os menores valores da característica relacionada com a contaminação orgânica (DBO).

Segundo Andrade et al. (2010) e Narciso e Gomes (2004), as águas subterrâneas normalmente apresentam teores mais elevados de $\mathrm{Ca}, \mathrm{Mg}, \mathrm{Na}$ e, principalmente, de STD e CE que as águas superficiais, o que não significa pior qualidade. $\mathrm{O}$ presente estudo corrobora tal afirmação, pois os grupos 1 e 2, formados exclusivamente por águas subterrâneas, apresentaram valores mais altos das características relacionadas com a salinidade da água. O grupo 3 foi formado por águas superficiais das microbacias sob uso de cafeicultura (período de estiagem) e de pastagem (período chuvoso), além das águas superficiais a montante e a jusante da área urbanizada (período chuvoso). Também fazem parte deste grupo as águas subterrâneas das microbacias sob a influência da floresta e cafeicultura (período de chuva). Percebe-se que esse grupo apresenta águas influenciadas por todos os usos do solo estudados.

As características desse grupo que diferiram estatisticamente dos outros foram a condutividade elétrica, os sólidos totais e o sódio, com valores intermediários, levando as águas deste grupo a apresentarem salinidade ligeiramente superior à do grupo 4 (menor salinidade das águas). O grupo 3, assim como o grupo 2, apresentou a menor concentração de $\mathrm{DBO}$, que não diferiu estatisticamente entre esses dois grupos.
Observa-se que esse grupo foi majoritariamente formado por águas coletadas no período de chuva, exceto as águas superficiais da microbacia sob cafeicultura, que foram coletadas no período de estiagem. Estas apresentam valores maiores das características relacionadas com a salinidade, principalmente cálcio e magnésio, comparativamente àquelas coletadas no período de chuva (classificadas no grupo 4). Isso ocorre devido a dois fatos: aplicação de doses de adubos e calcário que terminaram por contaminar as águas superficiais e diluição dos sais no período chuvoso, fato também constatado por Almeida e Schwarzbold (2003) ao avaliarem a qualidade das águas do Arroio da Cria Montenegro (RS).

Além disso, esse grupo, que majoritariamente é formado por águas superficiais, contém as águas subterrâneas das microbacias cobertas com floresta e cafeicultura coletadas no período de chuva. Provavelmente, essas águas que deveriam estar no grupo 1 ou 2 (grupo formado por águas subterrâneas), encontram-se no grupo 3 devido às suas características de salinidade (CE, ST e Na), que apresentam valores menores que as águas dos grupos 1 e 2, causada pela diluição dos sais pelas águas infiltradas durante as chuvas.

Para o grupo 4, a condutividade elétrica, os sólidos totais, a DBO, o cálcio, o magnésio e o sódio diferiram estatisticamente em relação aos outros grupos, sendo este o que apresentou as menores concentrações dos parâmetros relacionados com a salinidade da água (CE, ST, $\mathrm{Ca}, \mathrm{Mg}$ e $\mathrm{Na}$ ) e concentração intermediária do parâmetro DBO. Este grupo foi formado apenas por águas superficiais, coletadas na microbacia sob influência de floresta (períodos chuvoso e de estiagem), de cafeicultura (período chuvoso) e de pastagem (período de estiagem), além das seções fluviométricas a montante e jusante da área urbanizada (período de estiagem), apresentando, portanto, águas com qualidade influenciada por todos os usos avaliados.

As águas superficiais coletadas nas áreas sob influência da floresta e da cafeicultura apresentaram 
comportamento diferente dos outros pontos de coleta de água quanto à separação por período de estudo. O grupo 3 conteve as águas coletadas no período de chuva de todas as áreas estudadas, exceto da floresta e da cafeicultura, que se agruparam com as águas coletadas no período de estiagem (grupo 4). Isto pode estar relacionado às características dos ambientes aquáticos avaliados. As águas das microbacias com floresta e com cafeicultura são de ambiente lêntico, onde a diluição dos sais no período chuvoso fez com que estes pontos de coleta se agrupassem com as águas de ambiente lótico coletadas na época de estiagem e que apresentavam baixa concentração de sais.

Outra observação importante é quanto à área urbana, onde não se observou alteração da qualidade da água, já que as amostras coletadas a jusante e a montante mantiveram-se no mesmo grupo de qualidade. Talvez, esse comportamento seja consequência do baixo número de habitantes do distrito, que aliado ao poder de autodepuração e diluição das águas, não permitiu que fosse acusada contaminação por este uso.

A formação dos grupos foi mais influenciada pelo tipo de recurso hídrico (superficial ou subterrâneo), do que pelos períodos de coleta e tipo de cobertura do solo. Os grupos 1 e 2 foram formados por águas subterrâneas e o grupo 4 por águas superficiais; apenas o grupo 3 foi formado por ambos os recursos hídricos, mas dos seis pontos de coleta de água desse grupo, quatro foram superficiais e dois foram subterrâneos.

A separação dos grupos quanto ao tipo de recurso hídrico ocorreu devido às diferentes concentrações de $\mathrm{Ca}, \mathrm{Mg}, \mathrm{Na}, \mathrm{ST}$, STD e $\mathrm{CE}$, parâmetros relacionados com a mineralização das águas, que são tipicamente elevados em águas subterrâneas. Além disso, os grupos foram formados pela similaridade entre as concentrações das características de qualidade avaliadas, na qual aquelas relacionadas com a mineralização das águas foram as que mais influenciaram na segregação dos grupos.
De forma diferente, Palácio et al. (2009) ao avaliarem a similaridade das águas da bacia do Curu, no Ceará, perceberam que a definição dos agrupamentos da bacia estudada foi mais influenciada pela sazonalidade, o que é justificável, já que no Ceará a diferença entre as estações de chuva e estiagem são mais pronunciadas que no Espírito Santo.

\section{Conclusões}

Os resultados apresentados neste trabalho conduziram às seguintes conclusões:

Os parâmetros mais representativos da variabilidade da qualidade das águas superficiais e subterrâneas da sub-bacia hidrográfica do Córrego Horizonte foram: condutividade elétrica, sólidos totais, sólidos dissolvidos, turbidez, DBO, nitrato, $\mathrm{Ca}, \mathrm{Mg}$ e $\mathrm{Na}$.

A análise de agrupamento hierárquico formou quatro grupos distintos de qualidade, que diferiram quanto à concentração das características físicoquímicas e quanto ao tipo de recurso hídrico estudado (subterrâneo e superficial).

As características de qualidade relacionadas com a mineralização das águas $(\mathrm{Ca}, \mathrm{Mg}, \mathrm{Na}, \mathrm{ST}, \mathrm{STD}$ e $\mathrm{CE}$ ) foram as que mais influenciaram na segregação dos grupos.

Os períodos de coleta (chuva e estiagem) e o tipo de cobertura do solo (agrícola, pecuário, florestal e urbano) não influenciaram na segregação dos grupos formados.

\section{Agradecimentos}

À empresa FIBRIA e à CAPES pela concessão de bolsa de estudos e ao CNPq pela concessão de bolsa de produtividade em Pesquisa. 


\section{Referências}

ALMEIDA, M. A. B.; SCHWARZBOLD, A. Avaliação sazonal da qualidade das águas do Arroio da Cria Montenegro, RS com aplicação de um índice de qualidade de água (IQA). Revista Brasileira de Recursos Hídricos, Porto Alegre, v. 8, n. 1, p. 81-97, 2003.

ANDRADE, E. M.; LOPES, F. B.; PALÁCIO, H. A. Q.; AQUINO, D. N.; ALEXANDRE, D. M. B. Land use and groundwater quality: the case of Acaraú Irrigated Perimeter, Brazil. Revista Ciência Agronômica, Fortaleza, v. 41, n. 2, p. 208-215, 2010.

ANDRADE, E. M.; PALÁCIO, H.A. Q.; CRISÓSTOMO, L. A.; SOUZA, I. H.; TEIXEIRA, A. S. Índice de qualidade de água, uma proposta para o vale do rio Trussu, Ceará. Revista Ciência Agronômica, Fortaleza, v. 36, n. 2, p. 135-142, 2005.

ANDRADE, E. M.; ARAÚJO, L. F. P.; ROSA, M. F.; DISNEY, W.; ALVES, A. B. Seleção dos indicadores da qualidade das águas superficiais pelo emprego da análise multivariada. Engenharia Agrícola, Jaboticabal, v. 27, n. 3, p. 683-690, 2007a.

ANDRADE, E. M.; SILVEIRA, S. S.; AZEVEDO, B. M. Investigação da estrutura multivariada da evapotranspiração na região centro sul do Ceará pela análise de componentes principais. Revista Brasileira de Recursos Hídricos, Porto Alegre, v. 8, n. 1, p. 39-44, 2003.

ANDRADE, E. M.; ARAÚJO, L. F. P.; ROSA, M. F.; GOMES, R. B.; LOBATO, F. A. O. Fatores determinantes da qualidade das águas superficiais na bacia do Alto Acaraú, Ceará, Brasil. Ciência Rural, Santa Maria, v. 37, n. 6, p. 1791-1797, $2007 \mathrm{~b}$.

ASSOCIAÇÃO BRASILEIRA DE NORMAS TÉCNICAS - ABNT. Água - determinação de fósforo - método de ensaio: 12.772. Rio de Janeiro, 1992d. 9 p.

- Água determinação de metais - método de espectrometria de absorção atômica por chama: 13.810 . Rio de Janeiro, 1997. 4 p.

. Aguas - determinação de nitrogênio amoniacal - métodos de nesslerização, fenato e titulométrico: 10.560. Rio de Janeiro, 1988. 15 p.

. Águas - determinação de resíduos (sólidos) método gravimétrico: 10.664. Rio de Janeiro, 1989a. 7 p.

Águas - determinação da demanda bioquímica de oxigênio $(D B O)$ - Método de incubação $\left(20^{\circ} \mathrm{C}\right.$, cinco dias): 12.614. Rio de Janeiro, 1992a. 5 p.

Águas - determinação de nitrato - métodos do ácido cromotrópico e do ácido fenoldissulfônico: 12.620. Rio de Janeiro, 1992b. 5 p.
. Águas - determinação de nitrito - método da sulfanilamida e $N$-(1-naftil)-etilenodiamina: 12.619 . Rio de Janeiro, 1992c. 4 p.

. Águas minerais e de mesa-coliformes totais e fecais - determinação do número mais provável (N.M.P.) pela técnica dos tubos múltiplos: 11.259. Rio de Janeiro, 1989b. 3 p.

BHARDWAJ, V.; SINGH, D. S.; SINGH, A. K. Water quality of the Chhoti Gandak River using principal component analysis, Ganga Plain, India. Journal of Earth System Science, Bangalore, v. 119, n. 1, p. 117127, 2010.

BRAGA, B.; PORTO, M.; TUCCI, C. E. M. Monitoramento de quantidade e qualidade das águas. In: REBOUÇAS, A. C.; BRAGA, B.; TUNDISI, J. G. (Org.). Águas doces no Brasil: capital ecológico, uso e conservação. 3. ed. São Paulo: Escrituras, 2006. p. 145160 .

FERNANDES, F. B. P.; ANDRADE, E. M.; FONTENELE, S. B.; MEIRELES, A. C. M.; RIBEIRO, J. A. Análise de agrupamento como suporte à gestão qualitativa da água subterrânea no semiárido cearense. RevistaAgro@mbiente On-line, Boa Vista, v. 4, n. 2, p. 86-95, 2010.

GIRÃO, E. G.; ANDRADE, E. M.; ROSA, M. F.; ARAÚJO, L. F. P.; MEIRELES, A. C. M. Seleção dos indicadores da qualidade de água no Rio Jaibaras pelo emprego da análise da componente principal. Revista Ciência Agronômica, Fortaleza, v. 38, n. 1, p. 17-24, 2007.

HAIR, J. J. F.; ANDERSON, R. E.; TATHAM, R. L.; BLACK, W. C. Análise multivariada de dados. 5. ed. Porto Alegre: Bookman, 2005. 593 p.

KAZI, T. G.; ARAIN, M. B.; JAMALI, N.; AFRIDI, H. I.; SARFRAZ, R. A.; BAIG, J. A.; SHAH, A. Q. Assessment of water quality of polluted lake using multivariate statistical techniques: A case study. Ecotoxicology and Environmental Safety, Nova Iorque, v. 72, n. 2, p. 301309, 2009.

MENDIGUCHÍA, C.; MORENO, C.; GALINDORIANO, M. D.; GARCÍA-VARGAS, M. Using chemometric tools to assess antropogenic effects in river water a case study: Guadalquivir river (Spain). Analytica Chimica Acta, Amsterdam, v. 515, n. 1, p. 143-149, 2004.

MENDONÇA, F.; LEITÃO, S. A. M. Riscos e vulnerabilidade socioambiental urbana: uma perspectiva a partir dos recursos hídricos. GeoTextos, Salvador, v. 4, n. 1-2, p. 145-163, 2008. 
MENEZES, J. M.; PRADO, R. B.; SILAVA JÚNIOR, G. C.; MANSUR, K. L.; OLIVEIRA, E. S. Qualidade da água e sua relação espacial com as fontes de contaminação antrópicas e naturais: bacia hidrográfica do rio São Domingos- RJ. Engenharia Agrícola, Jaboticabal, v. 29, n. 4, p. 687-698, 2009.

NARCISO, M. G.; GOMES, L. P. Qualidade da água subterrânea para abastecimento público na Serra das Areias, Aparecida de Goiânia - GO. Revista Técnica da Sanepar, Curitiba, v. 21, n. 21, p. 4-18, 2004.

NORUSIS, M. J. SPSS Base system user's guide. Chicago: SPSS Inc, 1990.520 p.

PALÁCIO, H. A. Q.; ANDRADE, E. M.; LOPES, F. B.; ALEXANDRE, D. M. B.; ARRAES, F. D. D. Similaridade da qualidade das águas superficiais da bacia do Curu, Ceará. Ciência Rural, Santa Maria, v. 39, n. 9, p. 2494-2500, 2009.

PALÁCIO, H.A. Q.; ARAÚJO NETO, J. R.; MEIRELES, A. C. M.; ANDRADE, E. M.; SANTOS, J. C. N.; CHAVES, L .C. G. Similaridade e fatores determinantes na salinidade das águas superficiais do Ceará, por técnicas multivariadas. Revista Brasileira de Engenharia Agricola e Ambiental, Campina Grande, v. 15, n. 4, p. 395-402, 2011.
QUEIROZ, M. M. F.; IOST, C.; GOMES, S. D.; VILAS BOAS, M. A. Influência do uso do solo na qualidade da água de uma microbacia hidrográfica rural. Revista Verde de Agroecologia e Desenvolvimento Sustentável, Mossoró, v. 5, n. 4, p. 200-210, 2010.

R DEVELOPMENT CORE TEAM. $R$ : a language and environment for statistical computing, 2.8.1. Viena: $\mathrm{R}$ Foundation for Statistical Computing, 2008. Disponível em: <http://www.R-project.org $>$. Acesso em: 20 ago. 2011.

SIMEONOV, V.; ATRATIS, J. A.; SAMARA, C.; ZACHARIADIS, G.; VOUTSA, D.; ANTHEMIDIS, A.; SOFONIOU, M.; KOUIMTZIS, T. Assessment of the surface water quality in northern Greece. Water Research, Amsterdam, v. 37, n. 17, p. 119-124, 2003.

TOBISZEWSKI, M.; TSAKOVSKIB, S.; SIMEONOVC, V.; NAMIEŚNIKA, J. Surface water quality assessment by the use of combination of multivariate statistical classification and expert information. Chemosphere, v. 80, n. 7, p. 740-746, 2010.

VON SPERLING, M. Introdução à qualidade das águas $e$ ao tratamento de esgotos. 3. ed. Belo Horizonte: UFMG, 2005. $452 \mathrm{p}$. 